Rocha, RE, Sousa, RS \& Luz, LE. (2020). Research of Staphylococcus aureus in Nile Tilapia (Oreochromis niloticus) commercialized in the semi-arid region of Piauí. Research, Society and Development, 9(7):1-11, e222974034.

\title{
Pesquisa de Staphylococcus aureus em Tilápia do Nilo (Oreochromis niloticus)
} comercializada no semiárido piauiense

Research of Staphylococcus aureus in Nile Tilapia (Oreochromis niloticus) commercialized in the semi-arid region of Piauí

Investigación de Staphylococcus aureus en Tilapia del Nilo (Oreochromis niloticus) comercializada en la región semiárida de Piauí

Recebido: 28/04/2020 | Revisado: 29/04/2020 | Aceito: 04/05/2020 | Publicado: 08/05/2020

Rute Emanuela da Rocha

ORCID: https://orcid.org/0000-0002-3763-6665

Universidade Federal do Piauí, Brasil

E-mail: ruteemanuele@hotmail.com

Rener dos Santos de Sousa

ORCID: https://orcid.org/0000-0001-8073-1759

Universidade Federal do Piaú, Brasil

E-mail: reneer19@hotmail.com

Luís Evêncio da Luz

ORCID: https://orcid.org/0000-0003-2148-8175

Universidade Federal do Piauí, Brasil

E-mail: evencio@ufpi.edu.br

\section{Resumo}

Os Staphylococcus aureus são microrganismos frequentemente associados aos surtos de doenças transmitidas por alimentos, pela capacidade de produzirem e excretarem enterotoxinas termoestáveis. Este trabalho tem como objetivo a pesquisa de Staphylococcus aureus no peixe Tilápia do Nilo comercializado em municípios do semiárido piauiense. Coletou-se 50 amostras de tilápia, obtidas em feiras livres, supermercados e açougues de municípios do Vale do Guaribas no estado do Piauí. Utilizou-se $25 \mathrm{~g}$ de cada amostra de tilápia para homogeneização com $225 \mathrm{ml}$ de solução salina peptonada e para a pesquisa de Staphylococcus aureus, $1 \mathrm{ml}$ de cada amostra foi colocado em caldo BHI (infusão de cérebro e coração), em seguida, incubados a $37^{\circ} \mathrm{C}$ por 24 horas, onde aqueles tubos que se apresentaram turvos foram semeados por 
esgotamento em placas de ágar manitol. As colônias suspeitas no ágar manitol foram usadas para a identificação do Staphylococcus, sendo posteriormente realizadas Coloração de Gram, prova da catalase e prova da coagulase. Após realização da metodologia descrita, constatou-se presença de $S$. aureus em 38 das 50 amostras, perfazendo um total de $76 \%$ de amostras positivas para este microorganismo. Observou-se que a maioria dos estabelecimentos que comercializavam os pescados utilizados para amostragem não possuíam higiene necessária (uso de luvas pelos manipuladores, refrigeradores e utensílios para ser realizado corte higienizados, etc) facilitando contaminações. Faz-se necessário, além de uma fiscalização mais intensa por parte dos órgãos responsáveis, atenção por parte dos manipuladores e também dos consumidores, visando a diminuição de casos de contaminação.

Palavras-chave: Staphylococcus aureus; Oreochromis niloticus; contaminação de alimentos.

\begin{abstract}
Staphylococcus aureus are microorganisms often associated with foodborne disease outbreaks, for the ability to produce and excrete thermostable enterotoxins. This work has as objective the research of Staphylococcus aureus in Nile Tilapia fish commercialized in the semi-arid region of Piauí. Were collected 50 tilapia samples from free markets, supermarkets and butchers, $25 \mathrm{~g}$ of each tilapia sample was used for homogenization with $225 \mathrm{ml}$ peptone saline for research Staphylococcus aureus $1 \mathrm{ml}$ of each sample was placed in BHI broth (brain and heart infusion), after incubated at $37^{\circ} \mathrm{C}$ for 24 hours, where those turbid tubes were seeded by depletion on mannitol agar plates. Suspected mannitol agar colonies were used for identification of Staphylococcus, Gram staining was subsequently performed, catalase proof and coagulase proof. After completion of the methodology described, S. aureus was found in 38 of 50 samples, making a total of $76 \%$ of positive samples for this microorganism. It was observed that most establishments that marketed the fish used for sampling did not have necessary hygiene (use of gloves by handlers, refrigerators and utensils to perform sanitized cutting) facilitating contamination. It is necessary, futher a more intense supervision by the responsible agencies, attention from handlers as well as consumers, aiming at reducing cases of contamination.
\end{abstract}

Keywords: Staphylococcus aureus; Oreochromis niloticus; contamination of food.

\title{
Resumen
}

Staphylococcus aureus son microorganismos frecuentemente asociados con brotes de enfermidades transmitidas por alimentos, debido a su capacidad de producir y excretar enterotoxinas termoestables. Este trabajo tiene como objetivo investigar Staphylococcus aureus 
en peces de tilapia del Nilo comercializados en la región semiárida de Piauí. Se recogieron cincuenta muestras de tilapia, obtenidas en mercados abiertos, supermercados y carnicerías en los municipios de Vale do Guaribas en el estado de Piauí. Se usaron 25 g de cada muestra de tilapia para la homogeneización con $225 \mathrm{ml}$ de solución salina de peptona y para la búsqueda de Staphylococcus aureus, se colocó $1 \mathrm{ml}$ de cada muestra en caldo BHI (infusión de cerebro y corazón), luego se incubó a $37^{\circ} \mathrm{C}$ durante 24 horas, donde esos tubos que parecían nublados se sembraron por agotamiento en placas de agar con manitol. Se utilizaron colônias sospechosas en agar con manitol para identificar Staphylococcus, y se realizar ontinción de Gram, prueba de catalasa y prueba de coagulasa. Después de llevar a cabo la metodologia descrita, se encontro S.aureus en 38 de las 50 muestras, lo que representa un total de $76 \%$ de muestras positivas para este microorganismo. Se observo que la mayoría de los establecimientos que comercializaban el pescado utilizado para el muestreo no tenían la higiene necesaria (uso de guantes por parte de los manipuladores, refrigeradores y utensilios para limpiar, etc.) facilitando la contaminación. Es necesario, además de uma inspección más intensa por parte de los organismos responsables, atención por parte de los manipuladores y también de los consumidores, con el objetivo de reducir los casos de contaminación.

Palabras clave: Staphylococcus aureus; Oreochromis niloticus; contaminación de los alimentos.

\section{Introdução}

A Tilápia do Nilo (Orechromis niloticus) é uma importante espécie de pescado de origem africana, advinda da família dos ciclídeos, que foi introduzida nos diversos continentes. São peixes com grande rusticidade e facilidade de comercialização (Alves et al, 2015). As características como a carne branca de textura firme, sabor delicado, facilidade na filetagem, ausência de espinha em "Y" fazem com que esta espécie seja uma das mais preferidas pelos consumidores (Sousa et al., 2017).

A segurança e a qualidade dos produtos alimentares são aspectos de grande relevância, o que é confirmado pelo crescente número de leis que exigem a qualidade dos alimentos nas várias etapas da cadeia de produção. O frescor microbiológico é um importante critério de qualidade em pescado, já que o desenvolvimento microbiano é um dos principais fatores que levam à deterioração deste grupo alimentar (Gonçalves, 2011; Sousa et al., 2017).

Em pescado refrigerado, as bactérias psicrotróficas participam diretamente do processo de deterioração, pelo fato de se multiplicarem bem nessas condições. Esse grupo microbiano 
utiliza o pescado como substrato para realização de suas atividades metabólicas, produzindo substâncias que conferem aroma e sabor desagradável ao alimento (Soares \& Gonçalves, 2012; Porto, 2017). No Brasil, a Resolução RDC nº 12 de 2001 da Agência Nacional de Vigilância Sanitária (ANVISA) define os padrões microbiológicos para pescado.

De acordo com Tong et al. (2015) o Staphylococcus aureus é uma bactéria esférica, do grupo dos cocos gram-positivos, na maioria das vezes observada na pele e nas fossas nasais de indivíduos saudáveis. Porém pode provocar doenças, que podem ser uma simples infecção (espinhas, furúnculos e celulites) até infecções graves (pneumonia, meningite, endocardite, síndrome do choque tóxico, septicemia e outras). Os Staphylococcus são cocos Gram e catalasepositivos, com tamanho de 0,5 a 1,5 $\mu \mathrm{m}$ de diâmetro, sem motilidade, não esporulados e geralmente desprovidos da cápsula.

Os Staphylococcus aureus são microrganismos frequentemente associados aos surtos de doenças transmitidas por alimentos, pela capacidade de produzirem e excretarem enterotoxinas termoestáveis. O controle de estafilococos potencialmente patogênicos é essencial para a prevenção de infecções (Flores \& Melo, 2015). A eficiência da disseminação de S. aureus se deve, em parte, à capacidade desse microrganismo se adaptar rapidamente a diferentes ambientes, umidade, pressão osmótica ou deficiência de nutrientes, possibilitando não só a colonização do homem como do ambiente ao seu redor (Almeida et al., 2016).

O Território da Cidadania Vale Do Guaribas está localizado na região Nordeste, no estado do Piauí e é composto por 39 municípios, ocupando uma área de $22.693,41 \mathrm{~km}^{2}$. A população residente no Território totaliza 340.229 habitantes, sendo constituído por pequenos municípios. Do total de 39 municípios, 20 (51,3\%) possuem população de até 10 mil habitantes, sendo 12 (30,8\%) municípios com população inferior a 5 mil habitantes (MDA, 2015).

Nesse contexto, pesquisar o Staphylococcus aureus em Tilápia do Nilo (Oreochromis niloticus) é importante, uma vez que a ingestão desse alimento contaminado pode causar diversas doenças para a população, sendo um problema de saúde pública.

Este trabalho tem como objetivo a pesquisa de Staphylococcus aureus no peixe Tilápia do Nilo comercializado em municípios do semiárido piauiense, especificamente no Vale do Guaribas.

\section{Metodologia}

Coletou-se 50 amostras de tilápia, obtidas em feiras livres, supermercados e açougues de municípios do Vale do Guaribas no estado do Piauí, a saber Alegrete do Piauí, Bocaina, 
Campo Grande do Piauí, Francisco Santos, Inhuma, Ipiranga, Monsenhor Hipólito, Picos, Santa Cruz do Piauí, Santo Antônio de Lisboa, São João da Canabrava, São José do Piauí, Sussuapara e Wall Ferraz. As amostras adquiridas foram acondicionadas pelos próprios balconistas em embalagens contendo gelo reciclável e enviadas para o laboratório de Microbiologia de Alimentos da Universidade Federal do Piauí, Campus Senador Helvídio Nunes de Barros para o devido processamento das análises microbiológicas. As embalagens utilizadas no acondicionamento das amostras foram previamente desinfetadas com solução de álcool iodado a $5 \%$, para posterior abertura. Utilizou-se $25 \mathrm{~g}$ de cada amostra de tilápia, sendo posteriormente transferidas para um saco plástico tipo stomacher, previamente identificado, para homogeneização com $225 \mathrm{ml}$ de solução salina peptonada a $0.1 \%$ durante 60 segundos.

Para a pesquisa de Staphylococcus aureus, $25 \mathrm{~g}$ de cada amostra foram colocados em caldo BHI (infusão de cérebro e coração), em seguida, incubados a $37^{\circ} \mathrm{C}$ por 24 horas. Aqueles tubos que se apresentaram turvos foram semeados por esgotamento em placas de ágar manitol, que também foram incubados a esta temperatura 24 horas. As colônias suspeitas no ágar manitol foram usadas para a identificação do Staphylococcus, sendo posteriormente realizadas as seguintes provas: Coloração de Gram, sendo considerado resultado positivo a observação de bactérias com morfologia compatível às do gênero Staphylococcus; Prova da catalase, realizada em lâmina, onde utilizou-se as colônias que mostraram resultado positivo para Staphylococcus; Prova da coagulase, realizada primeiramente em lâmina e caso o resultado seja negativo foi realizada a prova em tubo.

\section{Resultados e Discussão}

Após realização da metodologia descrita anteriormente, foram tabulados em tabela e gráfico os resultados obtidos, onde constatou-se presença de Staphylococcus aureus em 38 das 50 amostras, perfazendo um total de $76 \%$ de amostras positivas para este microorganismo. A resolução RDC n 12 de 02 de janeiro de 2001 preconiza como parâmetro de qualidade microbiológica de pescado in natura, resfriados ou congelados não consumido cru o valor de $10^{3} \mathrm{UFC} / \mathrm{g}$ (Brasil, 2001).

Observou-se que a maioria dos estabelecimentos que comercializavam os pescados utilizados para amostragem não possuíam higiene necessária (como uso de luvas pelos manipuladores, refrigeradores e utensílios para ser realizado corte higienizados, etc) facilitando contaminações dos mesmos. Os alimentos podem sofrer contaminações de origem biológica, física ou química durante as diversas etapas do processamento, desde o momento do transporte, 
Research, Society and Development, v. 9, n. 7, e222974034, 2020

(CC BY 4.0) | ISSN 2525-3409 | DOI: http://dx.doi.org/10.33448/rsd-v9i7.4034

até as etapas de recebimento, armazenamento, preparação, distribuição e consumo, ou seja, a inexistência ou falta de condições higiênica-sanitária favoráveis pode desencadear, em qualquer etapa de produção, contaminação do alimento (Guilherme \& Esteves, 2017).

Tabela 01. Percentual de amostras que apresentaram resultado positivo para Staphylococcus aureus em municípios do vale do Guaribas.

\begin{tabular}{|c|c|c|}
\hline MUNICÍPIOS & $\mathbf{N}^{\circ}$ DE AMOSTRAS & $\begin{array}{c}\text { N }^{\circ} \text { AMOSTRAS } \\
\text { POSITIVAS } \\
\text { PARA } S . \text { AUREUS }\end{array}$ \\
\hline Alegrete do Piauí & 06 & 05 \\
\hline Bocaina & 03 & 03 \\
\hline Campo Grande do Piauí & 06 & 04 \\
\hline Francisco Santos & 04 & 03 \\
\hline Inhuma & 03 & 02 \\
\hline Ipiranga & 02 & 02 \\
\hline Monsenhor Hipólito & 04 & 04 \\
\hline Picos & 05 & 03 \\
\hline Santa Cruz do Piauí & 02 & 01 \\
\hline Santo Antônio de Lisboa & 03 & 02 \\
\hline São João da Canabrava & 03 & 02 \\
\hline São José do Piauí & 03 & 02 \\
\hline Sussuapara & 03 & 02 \\
\hline Wall Ferraz & 03 & 03 \\
\hline TOTAL & 50 & 38 \\
\hline
\end{tabular}

Fonte: Elaborado pelos autores através das pesquisas no laboratório de Microbiologia e Imunologia da UFPI/CSHNB 
Gráfico 01. Percentual de comparação de amostras contaminadas por S. aureus entre os municípios pesquisados.

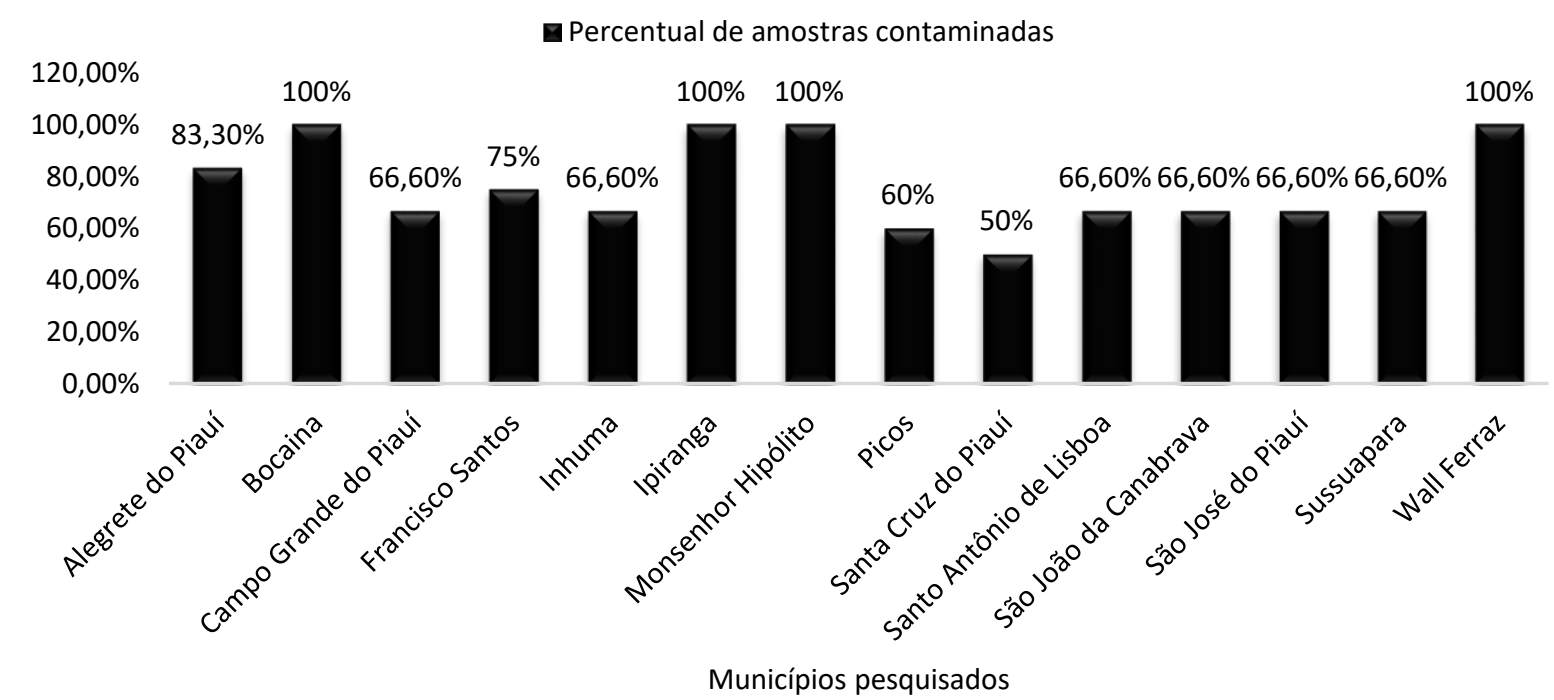

Fonte: Elaborado pelos autores.

$\mathrm{O}$ alto número de amostras contaminadas pode ser explicado por diversos fatores que envolvem toda sua cadeia produtiva até o momento da comercialização das mesmas, promovendo cada vez mais aumento de casos de intoxicação alimentar pelas toxinas formadas nos alimentos em decorrência da presença deste patógeno.

A intoxicação alimentar causada por este microrganismo é devido à contaminação de alimentos pelas exotoxinas (enterotoxinas) produzidas pela bactéria. Estas são termoestáveis e podem permanecer no alimento mesmo após o cozimento. Dentre as intoxicações alimentares de origem bacteriana, cerca de $45 \%$ destas no mundo estão relacionadas com esta bactéria. Após um curto período de incubação, de 1 a 6 horas após a ingestão do alimento, estas intoxicações são caracterizadas por náuseas, vômitos, dores abdominais e diarreia (Feitosa et al., 2017).

A distribuição de $S$. aureus é muito ampla, visto que essa bactéria é significativamente capaz de resistir a dessecação e ao frio, podendo permanecer viável por longos períodos em partículas de poeira (Almeida et al., 2016).

Faz-se importante mencionar a necessidade de uma higiene adequada dos utensílios empregados antes do momento da comercialização, onde percebeu-se que a maioria dos estabelecimentos em que foram adquiridas as amostras em questão não era feita higiene dos recipientes em que estavam os pescados, inclusive dos materiais usados para corte dos mesmos (facas, tábuas, etc). Segundo Manfrin (2013) "os fatores que mais colaboram com a 
contaminação do produto são o uso de equipamentos e instalações mal higienizados, bancadas sujas, presença de bactérias no moedor pela falta de limpeza".

De acordo com Medeiros et al. (2017) o manipulador é fundamental no que diz respeito à segurança dos alimentos, uma vez que, em contato com os mesmos, da origem até o momento da comercialização, pode se tornar um transmissor viável de agentes patogênicos de doenças alimentares, quando falhas e erros são cometidos. Assim sendo, o ser humano também possui uma alta capacidade para veicular patógenos de pessoa a pessoa, com graves riscos à saúde.

Como citado por Welker et al. (2010) "as camadas menos favorecidas da população geralmente são as mais afetadas pela contaminação alimentar, devido aos hábitos culturais da alimentação e à necessidade de optar por produtos com menor preço, geralmente de pior qualidade e mais contaminados", propiciando um aumento nos casos de doenças transmitidas por alimentos (DTA). Sendo assim é fundamental a educação em saúde e que a informação chegue à toda população, visando a erradicação desses casos.

No momento das coletas verificou-se a ausência de medidas profiláticas por parte dos manipuladores (manipulação de dinheiro, aparelhos celulares, etc ao mesmo tempo que se fazia o manejo do alimento). Dessa forma, a ocorrência de contaminação dos alimentos está associado à falhas na manipulação ou na conservação como cozimento ou descongelamento incorreto, aproveitamento de sobras e equipamentos higienizados incorretamente (Santana et al., 2010). É fundamental uma correta higienização do manipulador, onde ele mesmo pode ser uma fonte de contaminação, já que estafilococos estão naturalmente presentes nas vias nasais, na garganta, nas mãos e na pele (Rosa, 2014).

Segundo Damer (2014) “as análises microbiológicas permitem avaliar o alimento quanto às condições a que ele foi submetido, como o processamento, o armazenamento, a distribuição, a vida útil e os riscos à saúde a que a população possa ser exposta”. Por ser amplamente consumida, é de extrema importância oferecer ao consumidor um produto de adequada qualidade microbiológica, já que este pode ser responsável por ocasionar doenças para a população que dela faz uso (Rosina \& Monego, 2013).

\section{Considerações Finais}

Observou-se que a maioria das amostras apresentou colônias de $S$. aureus, o que é preocupante uma vez que sua comercialização é feita em larga escala, portanto há uma alta probabilidade de intoxicação alimentar de consumidores das mesmas. Faz-se necessário, além 
de uma fiscalização mais intensa por parte dos órgãos responsáveis, atenção por parte dos manipuladores e também dos consumidores, visando a diminuição de casos de contaminação.

\section{Referências}

Almeida, M.S.C., Mendonça, R.L., Freitas, M.Z.C. \& Vandesmet, L.C. (2016).

Staphylococcus aureus. Mostra Científica em Biomedicina, 1(1). Recuperado em 03 de maio de 2020 de http://201.20.115.105/home/bitstream/123456789/704/1/842-2907-1-PB.pdf

Alves, A.P.N.N., Verde, M.E.Q.L., Ferreira Júnior, A.E.C., Silva, P.G.B., Feitosa, V.P., Lima Júnior, E.M., Miranda, M.J.B. \& Moraes Filho, M.O. (2015). Avaliação microscópica, estudo histoquímico e análise de propriedades tensiométricas da pele de tilápia do Nilo. Rev Bras Queimaduras, 14 (3), 203-10.

BRASIL. (2001) Ministério da Saúde. Agência Nacional de Vigilância Sanitária. Resolução RDC N ${ }^{\circ} 12$, de 02 de janeiro de 2001. Regulamento Técnico sobre padrões microbiológicos de alimentos. Diário Oficial da União, Brasília, 2001. Recuperado de http://portal.anvisa.gov.br/documents/33880/2568070/RDC_12_2001.pdf/15ffddf6-37674527-bfac740a0400829b

Damer, J.R.S., Dill, R.E., Gusmão, A.A. \& Moresco, T.R. (2014) Contaminação de carne bovina moída por Escherichia coli e Salmonella sp. Revista Contexto \& Saúde Ijuí, 14 (26), 20-27.

Feitosa, A.C., Rodrigues, R.M., Torres, E.A.T. \& Silva, J.F.M. (2017). Staphylococcus aureus em alimentos. Revista Desafios, 4 (4), 15-31.

Flores, AM.P.C. \& Melo, C.B. (2015). Principais bactérias causadoras de doenças de origem alimentar. Revista Brasileira de Medicina Veterinária, 37 (1), 65-72.

Gonçalves, A.A. (2011) Tecnologia do pescado: ciência, tecnologia, inovação e legislação. São Paulo: Ateneu. 
Guilherme, D.L. \& Esteves, D.C. (2017). Doenças transmitidas por alimentos e água. Revista Conexão Eletrônica, 14 (1), 390-401.

Manfrin, L.C. (2013) Avaliação da qualidade microbiológica de carne moída bovina comercializada nos supermercados das cidades de Brasília e Taguatinga-DF. (Trabalho de Conclusão de Curso) Universidade de Brasília/UnB, Brasília, DF, Brasil.

Medeiros, M.G.G.A., Carvalho, L.R. \& Franco, R.M. (2017). Percepção sobre a higiene dos manipuladores de alimentos e perfil microbiológico em restaurante universitário. Ciência \& Saúde Coletiva, 22 (2), 383-392.

Ministério do Desenvolvimento Agrário (MDA). (2015). Vale Do Guaribas - PI. Recuperado em 03 de maio de 2020 de http://sit.mda.gov.br/download/caderno/caderno_territorial_096_Vale\%20do\%20Guaribas\%2 0-\%20PI.pdf

Porto, J.C.L. (2017). Estudo dos micro-organismos responsáveis pela deterioração em salsichas do tipo hot dog e as principais alterações físico-químicas. (Dissertação de Mestrado) Universidade Federal do Rio de Janeiro, Rio de Janeiro, RJ, Brasil.

Rosa, R.L. (2014). Características bacteriológicas da carne moída de bovina comercializada no município de Santo Antônio da Patrulha, RS. 2014. (Trabalho de Conclusão de Curso) Universidade Federal do Rio Grande do Sul/ UFRGS, Porto Alegre, RS, Brasil.

Rosina, A. \& Monego, F. (2013). Avaliação microbiológica da carne bovina moída nas redes de supermercados de Canoinhas/SC. Saúde Meio Ambiente, 2 (2), 55-64.

Santana, E.H.W., Beloti, V., Aragon-Alegro, L.C. \& Mendonça, M.B.O.C. (2010). Estafilococos em alimentos. Arquivos do Instituto Biológico, 77 (3), 545-554.

Soares, K.M.P. \& Gonçalves, A.A. (2012). Qualidade e segurança do pescado. Revista do Instituto Adolfo Lutz. 71 (1), 1-10. 
Sousa, F.A., Rodrigues, R.A., Arruda, F.A., Santos, W.L.M. \& Santos, T.M. (2017).

Caracterização higiênico-sanitária e tecnológica dos pescadores e da tilápia do nilo (Oreochromis niloticus) comercializada no mercado municipal de Salinas-MG. Revista Brasileira de Ciência Veterinária, 24 (4), 197-200.

Tong, S.Y.C., Davis J.S., Eichenberger, E., Holland, T.L. \& Fowler Jr., V.G. (2015).

Staphylococcus aureus Infections: Epidemiology, Pathophysiology, Clinical Manifestations, and Management. Clinical Microbiology Reviews, 28 (3), 603-661.

Welker, C.A.D., Both, J.M.C., Longaray, S.M., Haas, S., Soeiro, M. L. T. \& Ramos, R. C. (2010). Análise microbiológica dos alimentos envolvidos em surtos de doenças transmitidas por alimentos (DTA) ocorridos no estado do Rio Grande do Sul, Brasil. Revista brasileira de Biociências, 8 (1), 44-48.

\section{Porcentagem de contribuição de cada autor no manuscrito}

Rute Emanuela da Rocha - 40\%

Rener dos Santos de Sousa - 30\%

Luís Evêncio da Luz - 30\% 